degrees of synergy or an additive effect against $H$ influenzae in vitro. ${ }^{1718}$ It is concentrated in tissues to a similar extent as roxithromycin and is taken up by human phagocytes. The clinical efficacy of clarithromycin has been confirmed against $H$ influenzae and other pathogens causing a range of acute infections of the upper and lower respiratory tract acquired in the community, and the adverse reactions reported so far have been minor. ${ }^{19-21}$ Its gastrointestinal side effects in particular seem less than those with erythromycin as judged by the results of double blind comparative trials. ${ }^{19}$

What is the place of these new macrolides? The improved range of activity of clarithromycin, its twice daily administration, and its lower frequency of gastrointestinal symptoms, suggest that it may be a suitable alternative to erythromycin for monotherapy of many respiratory infections acquired in the community. Further comparative studies against the widely prescribed $\beta$-lactam drugs such as co-amoxyclav and the new oral cephalosporins are, however, needed before the optimal treatment can be determined for infections caused by $H$ influenzae. The therapeutic consequences of the tissue penetration of compounds such as azithromycin also need elucidating. A decision on whether these new macrolides represent an important advance in the treatment of respiratory infections must therefore await the results of further studies.

M J WOOD

Consultant Physician,

Department of Communicable and Tropical Diseases,

East Birmingham Hospital,

Birmingham B9 5ST

1 McGuire JM, Bunch RL, Anderson RC, Boaz HE, Flynn EH, Powell HM, et al. llotycin, a new antibiotic. Antibiot Chemother 1952;2:281-3.
2 Washington JA, Wilson WR. Erythromycin: a microbial and clinical perspective after 30 years of clinical use (second of two parts). Mavo Clin Proc 1985;60:271-8.

3 Grayston JT, Kuo CC, Wang SP, Altman T. A new Chlamydia psitraci strain, TWAR, isolated in acute respiratory tract infections. $N$ Engl f Med 1986;315:161-8.

4 Research Committee of the British Thoracic Society and the Public Health Laboratory Service. Community-acquired pneumonia in adults in British hospitals in 1982-83: a survey of aetiology mortality, prognostic factors and outcome. Qf Med 1987;62:195-220.

Mycoplasma pneumoniae [Editorial]. Lancet 1991;337:651-2.

6 Powell M. Chemotherapy for infections caused by Haemophilus influenzae: current problems and future prospects. I Antimicrob Chemother 1991;27:3-7.

7 Pullar T, Birtwell AJ, Wiles PG, Hay A, Feely MP. Use of a pharmacologic indicator to compare compliance with tablets prescribed to be taken once, twice, or three times daily. Clin Pharmacol Ther 1988; $44: 540-5$.

8 Fernandes PB. The macrolide revival: thirty five years after erythromycin. The Antimicrobic Newsletter 1987;4:25-36.

Chantot J-F, Bryskier A, Gasc J-C. Antibacterial activity of roxithromycin: a laboratory evaluation. 7 Antibiotics 1986;39:660-8.

10 Hardy DJ, Hensey DM, Beyer JM, Vojtko C, McDonald EJ, Fernandes PB. Comparative in vitro activities of new 14-, 15-, and 16-membered macrolides. Antimicrob Agents Chemother 1988;32:1710-9.

11 Fitzgeorge RB, Featherstone ASR, Baskerville A. Efficacy of azithromycin in the treatment of guinea pigs infected with Legionella pneumophila by aerosol. $\mathcal{f}$ Antimicrob Chemother 1990;25(suppl A): 101-8.

12 Foulds G, Shepard RM, Johnson RB. The pharmacokinetics of azithromycin in human serum and tissues. I Antimicrob Chemother 1990;25(suppl A):73-82.

13 Girard AE, Girard D, Retsema JA. Correlation of the extravascular pharmacokinetics of azithromycin with in-vivo efficacy in models of localized infection. $\mathcal{J}$ Antimicrob Chemother 1990:25(suppl A):61-71.

14 Steingrimsson O, Olafsson JH, Thorarinsson H, Ryan RW, Johnson RB, Tilton RC. Azithromycin in the treatment of sexually transmitted disease. F Antimicrob Chemother 1990;25(supp A): $109-14$

15 Davies BI, Maesen FPV, Gubbelmans R. Azithromycin (CP-62,993) in acute exacerbations of chronic bronchitis: an open clinical, microbiological and pharmacokinetic study. $f$ Antimicrob Chemother 1989;23:743-5

16 Fernandes PB, Ramer N, Rode RA, Freiberg L. Bioassay for A-56268 (TE-031) and identification of its major metabolite, 14-hydroxy-6-0-methyl erythromycin. Eur $\mathcal{F}$ Clin Microbiol Infect Dis 1988;7:73-6.

17 Hardy DJ, Swanson RN, Rode RA, Marsh K, Shipkowitz NL, Clement JJ. Enhancement of the in vitro and in vivo activities of clarithromycin against Hemophilus influenzae by 14-hydroxyclarithromycin, its major metabolite in humans. Antimicrob Agents Chemother 1990;34:1407-13.

18 Olsson-Liliequist B, Hoffman B-M. In-vitro activity of clarithromycin compared with it 14-hydroxy metabolite A-62671 against Haemophilus influenzae. $f$ Antimicrob Chemother 1991;27(suppl A):11-7.

19 Anderson G, Esmonde TS, Coles S, Macklin J, Carnegie C. A comparative safety and efficacy study of clarithromycin and erythromycin stearate in community-acquired pneumonia. $\mathcal{f}$ Antimicrob of clarithromycin and erythromycin
Chemother 1991;27(suppl A):117-24.

20 Karma P, Pukander J, Penttilä M, Savolainen S, Mikoski JL, Olén L, et al. The comparative efficacy and safety study of clarithromycin and amoxycillin in the treatment of outpatients with acute maxillary sinusitis. F Antimicrob Chemother 1991;27(suppl A):83-90.

21 Poirier $\mathrm{R}$. Comparative study of clarithromycin and roxithromycin in the treatment of communityacquired pneumonia. $f$ Antimicrob Chemother 1991;27(suppl A):109-16.

\title{
Improving survival after large bowel cancer
}

\section{Surgeons should look for the occult}

Hepatic metastases are present in up to one third of patients who undergo apparently curative excision of primary disease. ${ }^{1}$ Excision of these "occult" hepatic metastases, made possible by recent developments in hepatic imaging and resection, may substantially improve survival after surgery for the primary disease.

Little is known about the natural course of colorectal metastases. The differing ages of colorectal hepatic and extrahepatic metastases in the same patient and their prevalences in different organs suggest that dissemination to extrahepatic sites such as lung and bone is often by secondary metastasis from metastases that have already developed within the liver. ${ }^{2}$ Colorectal hepatic metastases are present for an average of four years before a patient's death. ${ }^{3}$ Neither conventional imaging ${ }^{45}$ nor the surgeon's hand at laparotomy ${ }^{6}$ is likely to detect metastases until they have reached a diameter of $2 \mathrm{~cm}-$ by which time three of their four years of growth will have elapsed.

Detecting hepatic metastases so late is not invariably hopeless as dissemination from the liver may occur very late in their history. That a primary large bowel cancer has already metastasised to the liver suggests that cells within hepatic metastases can metastasise. Despite this ability and the long interval that elapses before hepatic metastases become detectable, excision of the primary tumour and hepatic metastases cures about $3 \%$ of patients with metastases detected by conventional methods.' Several years may elapse between metastasis of large bowel cancer to the liver and secondary metastasis from the liver.

One reason for this late dissemination may be trapping within the liver of metastatic cells as they embolise from the primary tumour in the portal circulation. Experimental tumour studies suggest that successful metastasis will occur in only one in $10^{5}$ "attempts." This may explain some of the delay before metastasis from the liver to extrahepatic sites is successful.

Detecting "occult" hepatic metastases at primary surgery would reduce by about 16 months the three years that usually elapse before metastases become detectable by conventional means. ${ }^{9}$ During this three years secondary metastasis from the liver becomes more likely as metastatic volume doubles about five times, with cell numbers within an average metastasis increasing from about $10^{7}$ to $10^{9} .{ }^{3}$ More patients with large bowel cancer might be cured if more liver metastases were detected when the primary tumour was diagnosed, before secondary metastasis from the liver had occurred.

New techniques of hepatic imaging, particularly intraoperative ultrasonography $\mathrm{y}^{10-14}$ and magnetic resonance imaging, ${ }^{15}$ can show small metastases - as small as $4 \mathrm{~mm}$ in diameter in the case of intraoperative ultrasonography. 
Studies suggest that intraoperative ultrasonography can identify most patients with colorectal hepatic metastases at the time of surgery for the primary tumour.

Preliminary experience with intraoperative ultrasonography (A K Olsen, personal communication) suggests that resectable hepatic metastases will be found in about one in 10 patients undergoing apparently curative resection of primary large bowel cancer and that these can be excised by recently developed techniques for segmental resection. ${ }^{6} \mathrm{~A}$ further two in 10 patients will have unresectable hepatic disease because of too many deposits. Resection of conventionally detected hepatic metastases, which are apparently confined to the liver, produces long term survival in about one in four patients. ${ }^{6}$ Survival after resection of lesions detected by intraoperative ultrasonography may be better than after resection of the much larger tumours detected by conventional techniqueswhich have had longer to spread.

Patients in whom deposits detected by intraoperative ultrasonography are excised may also have hepatic metastases that are too small for detection by ultrasonography and may be missed by surgical resection. Thus detection of hepatic metastases by intraoperative ultrasonography may be more valuable in identifying patients in whom hepatic metastasis has occurred than in localising every deposit. Adjuvant intrahepatic infusion of fluorouracil has shown some survival advantage in large bowel cancer ${ }^{16}$ - presumably the benefit is in patients with occult hepatic metastases-and advanced colorectal hepatic metastases respond to intrahepatic infusion of fluorodeoxyuridine. ${ }^{17}$ Resection of hepatic metastases detected by intraoperative ultrasonography should therefore be followed by intrahepatic infusion of either fluorouracil or fluorodeoxyuridine to maximise the possibility of eradicating any microscopic foci of disease remaining within the liver in these "high risk" patients.
Randomised trials are needed in patients undergoing apparently curative resection of primary large bowel cancer to compare long term survival after conventional management with survival after intraoperative ultrasonography, resection of hepatic metastases, and intrahepatic infusion of either fluorouracil or fluorodeoxyuridine. As well as revealing any survival benefit, these trials will test our understanding of the biology of metastasis in large bowel cancer.

Senior Lecturer in Surgery,

T G ALLEN-MERSH

Westminster Hospital

London SWIP 2AP

1 Greenway B. Hepatic metastases from colorectal cancer: resection or not. Brf Surg 1988;75:513-9. 2 Weiss L, Grundman E, Torhorst J, Harveit F, Moberg I, Eber M, et al. Haematogenous metastatic patterns in colonic carcinoma: an analysis of 1541 necropsies. F Pathol 1986;150:195-203.

3 Finlay IG, Meek D, Brunton F, McArdle CS. Growth rate of hepatic metastases in colorectal carcinoma. Brf Surg 1988;75:641-4.

4 Smith TJ, Kemeny MM, Sugarbaker PH, Jones AE, Verness M, Shawker TH, et al. A prospective study of hepatic imaging in the detection of metastatic disease. Ann Surg 1982;195:486-91.

5 Matsui O, Takashima T, Kadoja M, Suzuki M, Hirose J, Kaweyama T, et al. Liver metastases from colorectal cancers: detection with CT during arterial portography. Radiology 1987;165:65-9.

6 Sugarbaker PH, Kemeny N. Management of metastatic cancer to the liver. Adv Surg 1989;22:1-56.

Steele G, Ravikumar TS. Resection of hepatic metastases from colorectal cancer. Ann Surg 1989;210:127-38.

8 Weiss L. Random and nonrandom processes in metastasis, and metastatic inefficiency. Invasion Metastasis 1983;3:193-207.

9 Palmer M, Petrelli NJ, Herrera L. No treatment option for liver metastases from colorectal adenocarcinoma. Dis Colon Rectum 1989;32:698-701.

10 Machi J, Isomoto H, Kurohiji J, Shirouzu K, Yamashita Y, Kakegawa T, et al. Detection of unrecognised liver metastases from colorectal cancers by routine use of operative ultrasonography. Dis Colon Rectum 1986;29:405-9.

11 Boldrini G, de Gaetano AM, Giovannini I, Castagneto M, Colagrande C, Castiglioni G. The systematic use of operative ultrasound for detection of liver metastases during colorectal surgery. World f Surg 1987;11:622-7.

12 Russo A, Sparacino G, Plaja S, Cajozza M, La Rosa C, Demma I, et al. Role of intraoperative ultrasound in the screening of liver metastases from colorectal carcinoma: initial experiences. f Surg Oncol 1989;42:149-55.

13 Olsen AK. Intraoperative ultrasound and the detection of liver metastases in patients with colorectal cancer. Br f Surg 1990;77:998-9.

14 Charnley RM, Morris DL, Dennison AR, Amar SS, Hardcastle JD. Detection of colorectal liver metastases using intraoperative ultrasound. $B r \mathcal{f}$ Surg 1991;78:45-8.

15 Ward BA, Miller DL, Frank JA, Dwyer AJ, Simmons JT, Chang R, et al. Detection of colorectal liver metastases: which imaging technique is best? Surgery 1989;105: 180-7.

16 Adjuvant $x$-ray and 5-FU infusional study (axis) protocol. Cambridge: MRC Cancer Trials Centre, 1990:6.

17 Allen-Mersh TG. Colorectal liver metastases: is no treatment still best? $\mathcal{F} R$ Soc Med 1989;82:2-3.

\section{Fibrinogen}

\section{An independent risk factor for cardiovascular disease}

Since the Northwick Park heart study showed that fibrinogen concentration was an independent risk factor for myocardial infarction ${ }^{12}$ five further epidemiological studies have produced prospective data on fibrinogen and cardiovascular events. ${ }^{3-7}$ All measured fibrinogen concentrations in large random samples of the population and related them to cardiovascular events several years later. From these studies fibrinogen concentration has emerged as an important and independent risk factor for stroke and myocardial infarction. In the most recent trial fibrinogen concentration, leucocyte count, and plasma viscosity were at least as predictive of coronary events as cholesterol concentration, diastolic blood pressure, and body mass index. ${ }^{7}$

That the fibrinogen concentration is raised after stroke ${ }^{8}$ and myocardial infarction' has been known for many years, although interpreting these findings is difficult given that fibrinogen is an acute phase protein and therefore likely to increase with inflammation or tissue necrosis. Recent work, however, suggests that fibrinogen concentration is raised before such events - for example, in patients with transient ischaemic attacks (p 605) ${ }^{1011}$ and with angina pectoris. ${ }^{12}$ More importantly perhaps, fibrinogen strongly predicts cardiovascular events in people with coronary heart disease ${ }^{9}$ and peripheral vascular disease ${ }^{13}$ and in survivors of a first stroke. ${ }^{14}$ It also predicts the progression of atherosclerotic carotid stenoses. ${ }^{15}$

This may be explained by fibrinogen concentration's positive correlation with nearly all other cardiovascular risk factors: age, hypertension, hyperlipoproteinaemia, smoking, diabetes, body mass index, stress, and lack of physical activity. ${ }^{16}$ Also relevant to an understanding of the links between fibrinogen concentration and cardiovascular disease are the findings that oral contraceptives increase the concentration of fibrinogen ${ }^{17}$ while moderate alcohol intake decreases it. ${ }^{18}$ Despite these associations fibrinogen concentration has emerged as an independent risk factor for cardiovascular disease. More than that, an increased fibrinogen concentration may be a common mechanism by which several major risk factors promote coronary artery disease. ${ }^{19}$

If this is so, how does fibrinogen damage the circulatory system? Several possibilities exist. It may promote a hypercoaguable state favouring the deposition of thrombus on atheromatous plaques, ${ }^{12}$ and it is an important determinant of blood rheology. ${ }^{16}$ Fibrinogen also links to platelet receptors, which is a precondition for platelet aggregation..$^{20}$ Multiple mechanisms exist whereby fibrinogen and its metabolites 